\title{
Alcohol Screening and Intervention Among United States Adults who Attend Ambulatory Healthcare
}

\author{
Joseph E. Glass, PhD, MSW' , Kipling M. Bohnert, PhD ${ }^{2,3}$, and Richard L. Brown, MD, MPH ${ }^{4}$ \\ 'School of Social Work, University of Wisconsin-Madison, Madison, WI, USA; ${ }^{2}$ Veterans Affairs Center for Clinical Management Research, VA Ann \\ Arbor Healthcare System, Ann Arbor, MI, USA; ${ }^{3}$ Department of Psychiatry, University of Michigan Medical School, Ann Arbor, MI, USA; ${ }^{4}$ Department \\ of Family Medicine and Community Health, School of Medicine and Public Health, University of Wisconsin-Madison, Madison, WI, USA.
}

\begin{abstract}
BACKGROUND: There is limited data on the extent to which indicated alcohol interventions are delivered in U.S. ambulatory care settings.

OBJECTIVE: To assess the receipt of alcohol-related services, including assessment of use, advice to reduce drinking, and information about alcohol treatment, during ambulatory care visits.
\end{abstract}

DESIGN: Secondary data analysis of the 2013 National Survey on Drug Use and Health, a cross-sectional, nationally representative survey of civilians in the non-institutionalized U.S. general population (response rate $71.7 \%$ ).

PARTICIPANTS: Adult ambulatory care users in the public use data file who did not obtain emergency or inpatient services $(n=17,266)$.

MAIN MEASURES: Measurements included respondents' alcohol consumption, heavy episodic drinking, alcohol use disorder, healthcare use, and receipt of alcoholrelated interventions.

KEY RESULTS: Approximately $71.1 \%$ of ambulatory care users received an alcohol assessment. Among pastmonth heavy episodic drinkers without an alcohol use disorder who reported receiving an alcohol assessment, $4.4 \%$ were advised to cut back. Among individuals with alcohol abuse and alcohol dependence who reported receiving an alcohol assessment, $2.9 \%$ and $7.0 \%$, respectively, were offered information about treatment.

CONCLUSIONS: Rates of alcohol screening and assessment were relatively high among adults who attended healthcare visits, but rates of intervention were low, even when individuals were assessed for use. Efforts are needed to expand delivery of interventions when patients are identified as positive for risky drinking, hazardous alcohol use, and alcohol use disorders during ambulatory care visits.

KEY WORDS: alcohol; ambulatory care; screening and brief intervention; treatment; referral.

J Gen Intern Med 31(7):739-45

DOI: $10.1007 / \mathrm{s} 11606-016-3614-5$

() Society of General Internal Medicine 2016

\section{INTRODUCTION}

Approximately $28 \%$ of adults in the United States (U.S.) consume alcohol above recommended limits ${ }^{1}$ and $7 \%$ meet

Received July 13, 2015

Revised January 8, 2016

Accepted January 29, 2016

Published online February 9, 2016 criteria for a past-year alcohol use disorder as defined by the Diagnostic and Statistical Manual of Mental Disorders, 4th edition. ${ }^{2,3}$ Unhealthy alcohol use is a leading cause of death ${ }^{4,5}$ and costs the U.S. approximately $\$ 223$ billion per year. ${ }^{6}$

The U.S. Preventive Services Task Force recommends that primary care settings deliver universal alcohol screening among adults and provide brief alcohol interventions to those with risky or hazardous drinking. ${ }^{7,8}$ Screening and brief intervention services reduce alcohol consumption and net healthcare costs among risky and problem drinkers who do not have alcohol use disorders of alcohol abuse or alcohol dependence. ${ }^{8-10}$ Referrals to specialized treatments may be indicated for those with alcohol use disorders or severe alcoholrelated health and social consequences. ${ }^{8,11,12}$

There is limited recent research, especially on a nationallevel, regarding the extent to which alcohol assessment, intervention, and referral is conducted in ambulatory care settings. Previous studies assessing alcohol intervention delivery have found the provision of these services to be lacking. ${ }^{13-16}$ Data from the 1997-1998 Healthcare for Communities survey, a national sample of adults from 60 randomly selected U.S. cities, estimated that $28.3 \%$ of healthcare users were asked about their alcohol or drug use during a past-year medical visit, and few received additional services. ${ }^{13}$ Another study of adults from 12 U.S. cities from 1998 to 2000 found that healthcare providers often did not deliver recommended care for patients with alcohol use disorders. ${ }^{14}$ For instance, $14.3 \%$ of adults who were known by their healthcare providers to drink excessively were advised to decrease their alcohol consumption, and $8.8 \%$ of adults with a known diagnosis of alcohol dependence were referred to treatment. ${ }^{14,15}$ Data from the Centers for Disease Control and Prevention Behavioral Risk Factor Surveillance System (BRFSS) indicated that in 1997, $16.1 \%$ of all patients, and $28.1 \%$ of excessive drinkers who attended a healthcare visit in the past 3 years had a doctor or health professional talk with them about their alcohol use. ${ }^{17}$ Data from the 2011 BRFSS estimated that $13.4 \%$ of excessive drinkers had such a discus$\operatorname{sion}^{16}$; however, the denominator for the 2011 estimate included those who did not receive healthcare.

A new study was deemed of interest because Medicare and Medicaid expanded reimbursement for alcohol screening and intervention in primary care settings in late 2011 under the Affordable Care Act, ${ }^{18,19}$ and the subsequent state of service 
delivery is not known. The current study identified the extent to which alcohol-related services were provided to U.S. adults in healthcare during 2013 and the nature of those services. Our study's primary objectives were to identify the prevalence of self-reported alcohol assessment and to describe the types of alcohol services provided to subpopulations of drinkers for which care was appropriate. Because the delivery of alcohol interventions in general healthcare varies by patient gender, ${ }^{17}$ and because many health plans now reimburse screening and brief intervention in general healthcare, ${ }^{18}$ we examined associations between gender, health insurance, and clinical severity with the specific types of alcohol-related care received.

\section{METHOD}

\section{Sample}

Study data are from the public use data of the 2013 National Survey on Drug Use and Health (NSDUH), an annual nationally representative, cross-sectional survey of alcohol and drug use, related disorders, and health among non-institutionalized individuals ages 12 years and older living in the U.S. ${ }^{20,21}$ The response rate in 2013 was $71.7 \%$. The survey used a multistage stratified sample design to produce unbiased estimates for the total targeted population. Respondents participated in computer-assisted, face-to-face interviews in their homes. The data file contained 55,160 respondents. The present study included respondents of age 18 years or older, because the U.S. Preventive Services Task Force recommends universal alcohol screening for adults only. ${ }^{7}$ Although alcohol-related services are provided in many healthcare settings, we were specifically interested in the provision of these services in ambulatory healthcare. Consequently, we restricted our analytic sample to adults who attended care in ambulatory settings, excluding those who also attended care in inpatient or emergency department settings. Respondents were asked about their receipt of healthcare in ambulatory care settings with the question, "How many times have you visited a doctor, nurse, physician assistant or nurse practitioner about your own health at a doctor's office, a clinic, or some other place?" Our primary analytic sample included $n=17,266$ participants.

\section{Measures}

New questions in the 2013 NSDUH survey assessed the receipt of alcohol interventions during visits to healthcare providers. Respondents who reported any past-year healthcare were questioned, "Did any doctor or other health care professional ask, in person or on a form, if you drink alcohol?" A positive response indicated the receipt of alcohol assessment. Those who consumed any alcohol in the past year and attended healthcare were asked to use a checklist to describe discussions that they had with doctors or other healthcare providers about their past-year alcohol use. The first three questions included "the doctor asked about how much I drink," "the doctor asked how often I drink," and "the doctor asked if I have any problems because of my drinking." We considered these items to indicate specific forms of alcohol assessment. We collapsed all four assessment items to create a dichotomous variable to indicate any past-year alcohol assessment. The final two checklist items asked about the receipt of alcohol-related interventions, including "the doctor advised me to cut down on my drinking," and "the doctor offered to give me more information about alcohol use and treatment for problems with alcohol use." We created dichotomous variables to indicate the receipt of each service. Advice to reduce drinking is an important component of brief intervention., ${ }^{7,22}$

The NSDUH also assessed specialty treatment or counseling for substance use. We considered respondents who said that they were treated for alcohol use only or for both alcohol and drugs in the past year to have obtained treatment or counseling.

NSDUH assessed alcohol abuse and dependence based on DSM-IV criteria. ${ }^{2}$ Past-month heavy episodic drinking was assessed with a per-occasion measurement of high-risk drinking. We coded women or men as positive for heavy episodic drinking if they consumed 4 or 5 or more drinks, respectively, in an occasion in the past month. ${ }^{23}$

Guidelines recommend specific levels of care based on clinical categorization. ${ }^{8,24}$ We derived four risk groups that aligned with these recommendations: (1) no heavy episodic drinking included respondents that consumed alcohol but did not engage in past-month heavy episodic drinking and did not meet DSM-IV criteria for an alcohol use disorder; (2) heavy episodic drinking included those who engaged in past-month heavy episodic drinking but did not have DSM-IV alcohol abuse or dependence; (3) alcohol abuse included those who met criteria for DSM-IV alcohol abuse, regardless of heavy episodic drinking, but did not meet criteria for DSM-IV alcohol dependence; and (4) alcohol dependence included respondents with DSM-IV alcohol dependence, regardless of heavy episodic drinking.

We selected covariates a priori for regression analyses that might be associated with both the primary predictors (gender, health insurance, or clinical severity) and the receipt of alcohol assessment or alcohol intervention. A count variable indicated the number of medical conditions that could contraindicate alcohol use, which were self-reported as diagnosed by a healthcare professional in the past year, including cirrhosis, heart disease, hepatitis, high blood pressure, HIV/AIDS, pancreatitis, strokes, and ulcers. The K6 scale assessed psychological distress in the past year, with a score of 13 or above having a sensitivity of 0.36 and specificity of 0.96 in detecting the presence of a DSM-IV mental health disorder. ${ }^{25} \mathrm{~A}$ dichotomous variable indicated coverage by any public or private health insurance. Sociodemographic characteristics included age, gender, race/ethnicity, education, family income, marital status, and employment.

\section{Statistical Analyses}

Analyses were conducted in Stata version $13.1^{26}$ and took into account the NSDUH complex sampling design. 
Sample Descriptive Statistics. We derived means or prevalence estimates of sociodemographic and clinical characteristics in the analytic sample $(n=17,266)$.

Prevalence of Care Among Alcohol use Risk Groups. To estimate the prevalence of specific types of care in the appropriate subpopulations of drinkers, ${ }^{8,11,12,24}$ and to compare the prevalence of care with other subpopulations of drinkers, we stratified prevalence estimates by alcohol use risk group. The assessment of alcohol use and problems is appropriate for all adults; thus, we calculated the prevalence of alcohol assessment regardless of respondents' alcohol consumption. Because the delivery of alcohol interventions would be predicated upon provider knowledge of alcohol consumption, we calculated the prevalence of advice to cut back and information about treatment among drinkers, conditional upon alcohol assessment $(n=9,992)$. Finally, to estimate the extent to which patients conformed to recommendations to seek help, we calculated the prevalence of alcohol-related treatment services or mutual help among drinkers who were offered information about treatment $(n=191)$. We examined for differences in the receipt of services by alcohol risk group using an adjusted Wald test.

Predictors of Appropriate Care. Next, we used logistic regression to examine covariate-adjusted predictors of the receipt of appropriate care, ${ }^{8,11,12,24}$ focusing these analyses on patient gender, health insurance status, and clinical severity. Alcohol assessment was analyzed among all adults, advice to cut back was analyzed among those with heavy episodic drinking without alcohol use disorders who received an alcohol assessment, and information about treatment was analyzed among those with alcohol use disorders who received an alcohol assessment.

\section{RESULTS}

Table 1 contains sociodemographic and clinical characteristics of adult ambulatory care users $(n=17,266)$, excluding those with inpatient stays or emergency department visits. Approximately $19.9 \%$ engaged in past-month heavy episodic drinking without meeting criteria for a DSM-IV alcohol use disorder, $3.5 \%$ met criteria for alcohol abuse, and $2.7 \%$ met criteria for alcohol dependence, per our hierarchical definition.

Table 2 contains prevalence estimates of the receipt of alcohol assessment and alcohol interventions during medical visits in the past year, as well as the receipt of alcohol-related treatment services or mutual help, stratified by alcohol use risk group. Approximately $71.1 \%$ of ambulatory care users received some form of alcohol assessment, and alcohol assessment was more common among those with heavy episodic drinking or alcohol use disorders. Of heavy episodic drinkers without alcohol use disorder who were assessed for alcohol use or problems, $4.4 \%$ received advice to cut back as recommended. ${ }^{8,11,12}$ Advice was more common among those with alcohol abuse $(8.7 \%)$ or alcohol dependence (22.0\%). Among those with alcohol abuse
Table 1. Sociodemographic and Clinical Characteristics of United States Adults who Attended Ambulatory Healthcare $(n=17,266)$

\begin{tabular}{|c|c|}
\hline & $\begin{array}{l}\text { Weighted \% or } \\
\text { Mean (SE) }\end{array}$ \\
\hline \multicolumn{2}{|l|}{ Age } \\
\hline $18-25$ & $12.2(0.3)$ \\
\hline $26-34$ & $13.3(0.5)$ \\
\hline $35-49$ & $25.7(0.6)$ \\
\hline$\geq 50$ & $48.9(0.7)$ \\
\hline Female & $54.6(0.7)$ \\
\hline \multicolumn{2}{|l|}{ Race/ethnicity } \\
\hline White & $68.9(0.7)$ \\
\hline Black & $9.9(0.5)$ \\
\hline American Indian or Alaskan Native & $0.4(0.1)$ \\
\hline Native Hawaiian or Pacific Islander & $0.3(0.0)$ \\
\hline Asian & $6.1(0.4)$ \\
\hline More than one race & $1.4(0.2)$ \\
\hline Hispanic & $13.0(0.4)$ \\
\hline \multicolumn{2}{|l|}{ Education } \\
\hline Less than high school & $9.7(0.4)$ \\
\hline High school graduate & $26.4(0.5)$ \\
\hline Some college & $27.2(0.6)$ \\
\hline College graduate & $36.8(0.7)$ \\
\hline \multicolumn{2}{|l|}{ Family income } \\
\hline$<\$ 20,000$ & $13.6(0.5)$ \\
\hline$\$ 20,000-49,999$ & $28.4(0.6)$ \\
\hline$\$ 50,000-64,999$ & $18.3(0.5)$ \\
\hline$\geq \$ 75,000$ & $39.7(0.8)$ \\
\hline Covered by health insurance & $90.5(0.3)$ \\
\hline \multicolumn{2}{|l|}{ Alcohol use risk groups } \\
\hline Abstinent & $27.7(0.7)$ \\
\hline No heavy episodic drinking & $46.1(0.5)$ \\
\hline Heavy episodic drinking & $19.9(0.2)$ \\
\hline Alcohol abuse & $3.5(0.2)$ \\
\hline Alcohol dependence & $2.7(0.6)$ \\
\hline Number of past-year alcohol use disorder symptoms & $0.3(0.0)$ \\
\hline Number of alcohol-related medical conditions & $0.5(0.0)$ \\
\hline Serious psychological distress & $8.4(0.3)$ \\
\hline Any past year illicit drug use & $13.1(0.4)$ \\
\hline
\end{tabular}

Estimates are weighted to represent the noninstitutionalized United States adult general population. Patients who attended emergency department or inpatient care were excluded from the sample

and alcohol dependence who received an alcohol assessment, $2.9 \%$ and $7.0 \%$, respectively, were offered information about alcohol treatment as recommended. ${ }^{8}$ Among adults who were assessed for alcohol use or problems and received information about alcohol treatment from their healthcare provider, $17.2 \%$ of those with alcohol abuse and $15.5 \%$ of those with alcohol dependence obtained alcohol-related treatment services or attended a mutual help program.

Table 3 shows the covariate-adjusted associations of gender, health insurance, alcohol use disorder symptoms, alcohol-related medical conditions, and ambulatory care visits with receiving an alcohol assessment during healthcare visits. Women were more likely than men to be assessed for alcohol use (OR $=1.3,95 \%$ $\mathrm{CI}=1.1-1.5)$, as were individuals with a greater number of alcohol use disorder symptoms $(\mathrm{OR}=1.2,95 \% \mathrm{CI}=1.1-1.2)$ or ambulatory care visits $(\mathrm{OR}=1.1,95 \% \mathrm{CI}=1.0-1.1)$.

Table 4 shows the covariate-adjusted associations of the focal predictor variables with receiving alcohol-related interventions during healthcare visits. Among heavy episodic drinkers who received an alcohol assessment, women were less likely than men to receive advice to cut back $(\mathrm{OR}=0.5,95 \% \mathrm{CI}=0.3-0.9)$, and those with a greater number of alcohol use disorder 
Table 2. Prevalence of Alcohol Assessment and Alcohol Interventions Among Adult Ambulatory Care Users

\begin{tabular}{|c|c|c|c|c|c|c|}
\hline \multicolumn{7}{|c|}{ Population: Adults with or without alcohol consumption $(n=17,266)$} \\
\hline & Overall $(n=17,266)$ & $\begin{array}{l}\text { No heavy episodic } \\
\text { drinking } \\
(n=11.379)\end{array}$ & $\begin{array}{l}\text { Heavy episodic } \\
\text { drinking } \\
(n=4,367)\end{array}$ & $\begin{array}{l}\text { Alcohol } \\
\text { abuse } \\
(n=852)\end{array}$ & $\begin{array}{l}\text { Alcohol } \\
\text { dependence } \\
(n=668)\end{array}$ & $F, p^{*}$ \\
\hline Outcome & $\%(\mathrm{SE})$ & & & & & \\
\hline Any alcohol assessment ${ }^{\dagger}$ & $71.1(0.6)$ & $67.4(0.8)$ & 80.8 & $85.9(2.2)$ & 81.4 & $45.4(3)^{*}$ \\
\hline \multicolumn{7}{|c|}{ Population: Adults who consumed alcohol and received an alcohol assessment $(n=9.992)$} \\
\hline & $\begin{array}{l}\text { Overall } \\
(n=9,992)\end{array}$ & $\begin{array}{l}\text { No heavy } \\
\text { episodic } \\
\text { drinking } \\
(n=5,316)\end{array}$ & $\begin{array}{l}\text { Heavy episodic } \\
\text { drinking } \\
(n=3,436)\end{array}$ & $\begin{array}{l}\text { Alcohol abuse } \\
(n=693)\end{array}$ & $\begin{array}{l}\text { Alcohol } \\
\text { dependence } \\
(n=547)\end{array}$ & $F, p^{*}$ \\
\hline Advised to cut back on drinking & $3.2(0.3)$ & $1.0(0.2)$ & $4.4(0.5)$ & $8.7(2.0)$ & $22.0(3.3)$ & $84.4(3) *$ \\
\hline $\begin{array}{l}\text { Offered information } \\
\text { about alcohol treatment }\end{array}$ & $1.3(0.2)$ & $0.7(0.1)$ & $1.4(0.3)$ & $2.9(1.1)$ & $7.0(1.9)$ & $22.6(3) *$ \\
\hline $\begin{array}{l}\text { Advice to cut back } \\
\text { or information about } \\
\text { alcohol treatment }\end{array}$ & $3.9(0.3)$ & $1.4(0.2)$ & $5.2(0.5)$ & $10.2(2.1)$ & $24.7(3.5)$ & $93.0(3)^{*}$ \\
\hline \multicolumn{7}{|c|}{ Population: Adults who were assessed and offered information about treatment $(n=191)$} \\
\hline & $\begin{array}{l}\text { Overall } \\
(n=191)\end{array}$ & $\begin{array}{l}\text { No heavy } \\
\text { episodic } \\
\text { drinking } \\
(n=59)\end{array}$ & $\begin{array}{l}\text { Heavy } \\
\text { episodic } \\
\text { drinking } \\
(n=68)\end{array}$ & $\begin{array}{l}\text { Alcohol } \\
\text { abuse } \\
(n=25)\end{array}$ & $\begin{array}{l}\text { Alcohol } \\
\text { dependence } \\
(n=39)\end{array}$ & $F, p^{*}$ \\
\hline $\begin{array}{l}\text { Utilized alcohol-related } \\
\text { treatment services or } \\
\text { mutual help }\end{array}$ & $8.1(2.2)$ & $7.5(4.0)$ & $0.5(0.5)$ & $17.2(6.4)$ & $15.5(6.8)$ & $4.1(3)^{*}$ \\
\hline $\begin{array}{l}\text { Specialty treatment } \\
\text { facility }\end{array}$ & $5.8(4.0)$ & $7.5(4.0)$ & $0.5(0.5)$ & $7.8(5.3)$ & $10.4(5.3)$ & $2.1(3)$ \\
\hline $\begin{array}{l}\text { Mutual help (e.g., } \\
\text { Alcoholics Anonymous) }\end{array}$ & $4.1(1.6)$ & $3.9(3.1)$ & $0.0(0.0)$ & $5.7(4.7)$ & $9.6(5.2)$ & $1.6(3)$ \\
\hline
\end{tabular}

${ }^{*} p<0.05$. Bolded values are statistically significant $(p<0.05)$

${ }^{*} n=401$ had missing data on alcohol assessment. For the outcome of alcohol assessment, the "no heavy episodic drinking" group included individuals who were abstinent from alcohol use. Cluster-adjusted F-test statistics are displayed. The numerator degrees of freedom (df) for all tests was 3, rounded to the nearest integer

symptoms $(\mathrm{OR}=2.1,95 \% \mathrm{CI}=1.6-2.9)$ or alcohol-related medical conditions $(\mathrm{OR}=2.8,95 \% \mathrm{CI}=1.7-4.4)$ were more likely to receive advice. Among adults with alcohol use disorders who received an alcohol assessment, women were less likely than men $(\mathrm{OR}=0.3,95 \% \mathrm{CI}=0.1-0.7)$ to receive information about alcohol treatment, and those with a greater number of alcohol use disorder symptoms $(\mathrm{OR}=1.4,95 \% \mathrm{CI}=1.1-1.8)$ were more likely to receive information about alcohol treatment. Health insurance was not significantly associated with receiving these services. Because few individuals with alcohol use disorders received information about treatment $(n=64)$, and just 17 obtained alcohol treatment or mutual help, we did not investigate predictors of the receipt of these specialized services.

We conducted sensitivity analyses among ambulatory care users who also received care in emergency or inpatient settings $(n=28,212)$. Approximately $73.4 \%$ of individuals with or without alcohol consumption received an alcohol assessment, and $4.1 \%$ of heavy episodic drinkers without an alcohol use disorder who were assessed received advice to cut back. Approximately $3.2 \%$ of those with alcohol abuse and $11.1 \%$ of those with alcohol dependence who were assessed were offered information about treatment.

\section{DISCUSSION}

This study analyzed survey data from a nationally representative sample of U.S. adults to identify the prevalence of alcohol assessment during routine healthcare visits, describe the types of alcohol-related interventions received by those who drink alcohol, and identify clinical correlates of receiving these services in ambulatory care settings. Seventy-one percent of adults with an ambulatory care visit were assessed for alcohol misuse. However, few patients for whom specific interventions were indicated received them, even though they received some type of alcohol assessment. Fewer than one in 25 adult heavy episodic drinkers without an alcohol use disorder received advice to cut back on their drinking and fewer than one in ten adults with alcohol dependence who attended ambulatory care received information about alcohol treatment from their healthcare providers. Among those with alcohol use disorders who obtained information about treatment from their healthcare provider, approximately one in six obtained alcohol-related treatment services or mutual help.

Table 3. Predictors of Alcohol Assessment Among Adult Ambulatory Healthcare Users $(n=17,266)$

\begin{tabular}{ll}
\hline \hline Predictors of alcohol assessment & OR (95 \% CI) \\
\hline Female & $\mathbf{1 . 3}(\mathbf{1 . 1}-\mathbf{1 . 5})$ \\
Covered by health insurance & $1.1(0.9-1.4)$ \\
Number of alcohol use disorder symptoms & $\mathbf{1 . 2}(\mathbf{1 . 1}-\mathbf{1 . 2})$ \\
Number of alcohol-related medical conditions & $1.0(0.9-1.2)$ \\
Number of ambulatory care visits & $\mathbf{1 . 1}(\mathbf{1 . 0}-\mathbf{1 . 1})$ \\
\hline
\end{tabular}

$n=401$ participants had missing data on alcohol assessment. Bolded values are statistically significant $(p<0.05)$. Additional covariates (not shown for brevity) included age, race/ethnicity, education, income, marital status, employment, serious psychological distress, and illicit drug use 
Table 4. Correlates of Receiving Appropriate Alcohol-Related Interventions Among Adult Ambulatory Healthcare Users Who Received an Alcohol Assessment

\begin{tabular}{lll}
\hline \hline Type of appropriate care and population & $\begin{array}{l}\text { Advice to cut back among } \\
\text { heavy episodic drinkers } \\
\text { without an alcohol use } \\
\text { disorder }(\boldsymbol{n}=\mathbf{3 , 4 3 6})\end{array}$ & $\begin{array}{l}\text { Information about treatment } \\
\text { among those with alcohol } \\
\text { use disorders }(\boldsymbol{n}=\mathbf{1 , 2 4 0})\end{array}$ \\
\hline Variable & OR $(95 \% \mathrm{CI})$ & $\mathrm{OR}(95 \% \mathrm{CI})$ \\
Female & $\mathbf{0 . 5}(\mathbf{0 . 3 - 0 . 9 )}$ & $\mathbf{0 . 3}(\mathbf{0 . 1}-\mathbf{0 . 7})$ \\
Covered by health insurance & $2.1(0.7-6.0)$ & $4.2(0.8-23.1)$ \\
Number of alcohol use disorder symptoms & $\mathbf{2 . 1}(\mathbf{1 . 6}-\mathbf{2 . 9})$ & $\mathbf{1 . 4}(\mathbf{1 . 1}-\mathbf{1 . 8})$ \\
Number of alcohol-related medical conditions & $\mathbf{2 . 8}(\mathbf{1 . 7 - 4 . 4 )}$ & $2.4(0.8-7.3)$ \\
Number of ambulatory care visits & $1.0(0.9-1.1)$ & $0.9(0.8-1.1)$ \\
\hline
\end{tabular}

Bolded values are statistically significant $(p<0.05)$. Additional covariates (not shown for brevity) included age, race/ethnicity, education, income, marital status, employment, serious psychological distress, and illicit drug use. American Indian or Alaskan Native and Native Hawaiian or Pacific Islanders were excluded from the analyses due to low bivariate cell counts. Marital status was dichotomized to currently married vs. not currently married

With new data from all 50 states and the District of Columbia, the current study echoes previous findings of large quality gaps in alcohol services delivered in general healthcare settings. While the Centers for Disease Control and Prevention BRFSS surveys in 1997 and 2011 did not make distinctions between alcohol assessment and alcohol intervention, ${ }^{16,17}$ and other studies conducted before 2000 did not draw upon national data, ${ }^{13-15}$ all surveys suggest that few adults with alcohol problems receive indicated alcohol interventions. These nationally representative data indicate that despite high rates of alcohol assessment in 2013 compared to previous surveys, rates of alcohol interventions remain low.

An ongoing challenge is to increase the provision of services for those with positive alcohol assessments. The current data indicate that assessment processes may trigger some interventions and referrals, and that professionals more frequently provide services to patients with more serious problems. In the Department of Veterans Affairs (VA) Healthcare System, $90 \%$ of patients underwent alcohol screening with a validated instrument in $2004,{ }^{27}$ and $58 \%$ of outpatients with positive screens for alcohol misuse received advice to abstain or reduce drinking, feedback linking alcohol use to medical conditions, or referrals to addiction treatment in 2008. ${ }^{28}$ From 2004 to 2008, rates of alcohol-related advice and other brief intervention in the VA increased significantly during the implementation of computerized reminders and decision support for alcohol screening and intervention in conjunction with performance monitoring. ${ }^{28}$ These strategies may be helpful for healthcare systems that lag in alcohol screening and intervention delivery. Another strategy may involve expansion of healthcare teams with dedicated, trained staff to deliver assessments, interventions, referrals, and follow-up care for patients who screen positive on questionnaires, ${ }^{29}$ in order to decrease burden on primary care providers.

Most patients with alcohol use disorders who were offered information about treatment did not receive treatment. Because brief alcohol interventions appear to be ineffective for alcohol dependence, ${ }^{30}$ and because there is a lack of evidence that brief interventions are efficacious in linking patients to counseling or treatment for alcohol problems, ${ }^{31}$ more efficacious clinical management options and referral strategies are needed in healthcare settings. ${ }^{32-34}$ Alcohol pharmacotherapy is efficacious ${ }^{35}$ and alcohol care management in primary care settings may be helpful, ${ }^{36,37}$ but current evidence for chronic care management for alcohol dependence in primary care settings appears mixed. ${ }^{36,38}$ Future national surveys should track whether and where pharmacotherapy was offered and received by patients with alcohol use disorder.

The current findings suggest disparities in service delivery between women and men. Although women were more likely to be assessed for alcohol problems than men, they were less likely to receive any advice to reduce drinking or information about alcohol treatment, even when adjusting for clinical severity. With exceptions, ${ }^{39}$ prior studies have found women to be less likely to obtain various alcohol-related services. ${ }^{40-42}$ Because the stigma of alcohol misuse ${ }^{43-45}$ may be higher among women, ${ }^{46}$ they may be more likely to under-report their alcohol use and conceal the severity of their alcohol problems.

These findings should be interpreted within the context of several limitations. Survey items did not distinguish between alcohol screenings with a validated tool and informal assessment methods that may have high specificity but poor sensitivity. ${ }^{47}$ Moreover, the validity of self-reported alcohol assessment is not known. The self-report of receipt of advice about drinking is comparable to documented advice in medical records and is used as a standard to evaluate the receipt of brief intervention in confidential surveys, ${ }^{22,27}$ and healthcare visits and specialty treatment utilization can be recalled with good accuracy. ${ }^{48,49}$ Alcohol problems may have only occurred after participants' healthcare visits. The heavy episodic drinking measure corresponds well to the daily drinking limits set by the National Institute on Alcohol Abuse and Alcoholism, ${ }^{1}$ but weekly drinking limits were not assessed. Almost all adults who exceed weekly drinking limits also exceed daily limits. ${ }^{50}$ The analyses that were conditional upon receiving alcohol assessment do not necessarily indicate whether or not healthcare providers were aware of respondents' misuse.

In summary, data from the current study indicate that most patients in the U.S. receive some form of alcohol assessment in healthcare settings. Nonetheless, most patients for whom interventions and referrals are indicated do not receive them, 
despite expanded reimbursement for screening and brief intervention under the Affordable Care Act, ${ }^{18,19}$ and despite continued recommendations by the US Preventive Services Task Force. $^{7,8}$ Further policy change, such as stronger financial incentives to meet rigorous quality metrics, ${ }^{51}$ may be needed to enhance delivery of alcohol screening and intervention in general healthcare settings.

Contributors: Dr. Glass conceptualized the study's design, conducted the statistical analyses, and prepared drafts of the manuscript. Dr. Bohnert and Dr. Brown provided substantive guidance regarding the design of the analyses, interpretation of the results, and critical revision of the manuscript. All authors approved the final manuscript. All authors had full access to all the data in the study and take responsibility for the integrity of the data and the accuracy of the data analysis.

Corresponding Author: Joseph E. Glass, PhD, MSW; School of Social WorkUniversity of Wisconsin-Madison, 1350 University Ave., Madison, WI 53706, USA (e-mail:jglass2@wisc.edu).

\section{Compliance with Ethical Standards:}

Funding Sources: Dr. Bohnert is supported by a Department of Veterans Affairs HSR\&D Career Development Award (CDA 11-245). The Department of Veterans Affairs had no role in the design and conduct of the study; collection, management, analysis, and interpretation of the data; preparation, review, or approval of the manuscript; and decision to submit the manuscript for publication.

Prior Presentations: This work was presented in a symposium at the 2015 Addiction Health Services Research Conference and the 2015 Annual Conference of the Association for Medical Education and Research in Substance Abuse.

Conflict of Interest: Dr. Glass and Dr. Bohnert report no conflicts of interest. Dr. Brown is owner and CEO of Wellsys, LLC, which helps healthcare settings deliver alcohol screening and intervention and similar services for other behavioral risks and disorders.

Human Subjects: This research did not require prior IRB approval, per the University of Wisconsin-Madison Existing Datasets Policy. The data are published and publically available without restriction and the researchers do not have access to links that would connect the data to individuals for whom they were derived.

\section{REFERENCES}

1. National Institute on Alcohol Abuse and Alcoholism. Rethinking Drinking: Alcohol and Your Health. Rockville, MD: National Institutes of Health; 2010 .

2. American Psychiatric Association. Diagnostic and Statistical Manual of Mental Disorders (4th Edition, Text Revised). Washington, DC: American Psychiatric Association; 2000

3. Grant BF, Stinson FS, Dawson DA, et al. Prevalence and co-occurrence of substance use disorders and independent mood and anxiety disorders: results from the National Epidemiologic Survey on Alcohol and Related Conditions. Arch Gen Psychiatry. 2004;61(8):807-16. doi:10.1001/archpsyc.61.8.807.

4. Mokdad AH, Marks JS, Stroup DF, Gerberding JL. Actual causes of death in the United States, 2000. JAMA. 2004;291(10):1238-45. doi:10. 1001/jama.291.10.1238291/10/1238.

5. Center for Disease Control and Prevention. Alcohol and public health: Data, trends, and maps. http://www.cdc.gov/alcohol/quickstats/binge_ drinking.htm. Published 2014. Accessed July 3, 2014.

6. Bouchery EE, Harwood HJ, Sacks JJ, Simon CJ, Brewer RD. Economic costs of excessive alcohol consumption in the U.S., 2006. Am J Prev Med. 2011;41(5):516-24. doi:10.1016/j.amepre.2011.06.045.

7. U.S. Preventive Services Task Force. Screening and behavioral counseling interventions in primary care to reduce alcohol misuse: recommendation statement. Ann Intern Med. 2004;140(7):554-6.
8. U.S. Preventive Services Task Force. Screening and behavioral counseling interventions in primary care to reduce alcohol misuse: recommendation statement. Am Fam Physician. 2014;89(12):Online.

9. Fleming MF, Mundt MP, French MT, Manwell LB, Stauffacher EA, Barry KL. Benefit-cost analysis of brief physician advice with problem drinkers in primary care settings. Med Care. 2000;38(1):7-18.

10. Moyer A, Finney JW, Swearingen CE, Vergun P. Brief interventions for alcohol problems: a meta-analytic review of controlled investigations in treatment-seeking and non-treatment-seeking populations. Addiction. 2002;97(3):279-92.

11. Babor TF, McRee BG, Kassebaum PA, Grimaldi PL, Ahmed K, Bray J. Screening, Brief Intervention, and Referral to Treatment (SBIRT): toward a public health approach to the management of substance abuse. Subst Abus. 2007;28(3):7-30.

12. National Institute on Alcohol Abuse and Alcoholism. Treatment for Alcohol Problems: Finding and Getting Help. Department of Health and Human Services; 2014.

13. Edlund MJ, Unutzer J, Wells KB. Clinician screening and treatment of alcohol, drug, and mental problems in primary care: results from healthcare for communities. Med Care. 2004;42(12):1158-66.

14. McGlynn EA, Asch SM, Adams J, et al. The quality of health care delivered to adults in the United States. N Engl J Med. 2003;348(26):263545. doi:10.1056/NEJMsa022615.

15. McGlynn EA, Asch SM, Adams J, et al. The Quality of Health Care Delivered to Adults in the United States (Appendix).; 2006.

16. McKnight-Eily LR, Liu Y, Brewer RD, et al. Vital signs: communication between health professionals and their patients about alcohol use-44 states and the District of Columbia, 2011. MMWR Morb Mortal Wkly Rep. 2014;63(1):16-22.

17. Arndt S, Schultz S, Turvey C, Petersen A. Screening for alcoholism in the primary care setting: are we talking to the right people? J Fam Pract. 2002;51(1):41-6.

18. Centers for Medicare and Medicaid Services. Decision Memo for Screening and Behavioral Counseling Interventions in Primary Care to Reduce Alcohol Misuse.; 2011. http://www.cms.gov/medicare-coverage-database/details/nca-decision- memo.aspx?NCAId $=249$.

19. Department of Health and Human Services Centers for Medicare \& Medicaid Services. Screening and Behavioral Counseling Interventions in Primary Care to Reduce Alcohol Misuse.; 2011. http://www.cms.gov/ Outreach-and-Education/Medicare-Learning-Network-MLN/MLNMattersArticles/downloads/MM7633.pdf.

20. Center for Behavioral Health Statistics and Quality. National Survey on Drug Use and Health (NSDUH): Summary of Methodological Studies, 1971-2014. Rockville, MD: Substance Abuse and Mental Health Services Administration; 2014.

21. Substance Abuse and Mental Health Services Administration. Results from the 2013 National Survey on Drug Use and Health (NSDUH): Summary of National Findings. Rockville, MD: Substance Abuse and Mental Health Services Administration; 2014.

22. Lapham GT, Rubinsky AD, Shortreed SM, et al. Comparison of Providerdocumented and Patient-reported Brief Intervention for Unhealthy Alcohol Use in VA outpatients. Drug Alcohol Depend. 2015. doi:10.1016/j. drugalcdep.2015.05.027.

23. Courtney KE, Polich J. Binge drinking in young adults: Data, definitions, and determinants. Psychol Bull. 2009;135(1):142-56. doi:10.1037/a0014414.

24. National Institute on Alcohol Abuse and Alcoholism. Helping Patients Who Drink Too Much: A Clinician's Guide. Bethesda, MD; 2005.

25. Kessler RC, Barker PR, Colpe LJ, et al. Screening for Serious Mental Illness in the General Population. Arch Gen Psychiatry. 2003;60(2):184. doi:10.1001/archpsyc.60.2.184.

26. StataCorp. Stata Statistical Software: Release 13. College Station, TX: StataCorp, LP; 2013.

27. Bradley KA, Williams EC, Achtmeyer CE, Volpp B, Collins BJ, Kivlahan DR. Implementation of evidence-based alcohol screening in the Veterans Health Administration. Am J Manag Care. 2006;12(10):597-606.

28. Lapham GT, Achtmeyer CE, Williams EC, Hawkins EJ, Kivlahan DR, Bradley KA. Increased documented brief alcohol interventions with a performance measure and electronic decision support. Med Care. 2012;50(2):179-87. doi:10.1097/MLR.0b013e3181e35743.

29. Brown RL, Moberg PD, Allen JB, et al. A team approach to systematic behavioral screening and intervention. Am J Manag Care. 2014;20(4):e113-21.

30. Saitz R. Alcohol screening and brief intervention in primary care: Absence of evidence for efficacy in people with dependence or very heavy drinking. Drug Alcohol Rev. 2010;29(6):631-40. doi:10.1111/j.1465-3362.2010. 00217.x. 
31. Glass JE, Hamilton AM, Powell BJ, Perron BE, Brown RT, Ilgen MA. Specialty substance use disorder services following brief alcohol intervention: a meta-analysis of randomized controlled trials. Addiction. 2015;110(9): 1404-15. doi:10.1111/add.12950.

32. Saitz R. "SBIRT" is the answer? Probably not. Addiction. 2015;110(9):1416-17. doi:10.1111/add.12986.

33. Cucciare M, Timko C. Bridging the gap between medical settings and specialty addiction treatment. Addiction. 2015;110(9):1417-1419. doi:10. 1111 /add. 12977.

34. Glass JE. Challenges ahead in developing and testing referral to treatment interventions. Addiction. 2015;110(9): 1419-20. doi:10.1111/add.13039.

35. Jonas DE, Amick HR, Feltner C, et al. Pharmacotherapy for adults with alcohol use disorders in outpatient settings: a systematic review and metaanalysis. JAMA. 2014;311(18):1889-1900. doi:10.1001/jama.2014.3628.

36. Oslin DW, Lynch KG, Maisto SA, et al. A randomized clinical trial of alcohol care management delivered in Department of Veterans Affairs primary care clinics versus specialty addiction treatment. J Gen Intern Med. 2014;29(1):162-8. doi:10.1007/s11606-013-2625-8.

37. Willenbring ML, Olson DH. A randomized trial of integrated outpatient treatment for medically ill alcoholic men. Arch Intern Med. 1999;159(16): 1946-1952.

38. Saitz R, Cheng DM, Winter M, et al. Chronic Care Management for Dependence on Alcohol and Other Drugs: The AHEAD Randomized Trial. JAMA. 2013;310(11):1156. doi:10.1001/jama.2013.277609.

39. Glass JE, Perron BE, Ilgen MA, Chermack ST, Ratliff S, Zivin K. Prevalence and correlates of specialty substance use disorder treatment for Department of Veterans Affairs Healthcare System patients with high alcohol consumption. Drug Alcohol Depend. 2010;112(1-2):150-5. doi:10. 1016/j.drugalcdep.2010.06.003.

40. Dobscha SK, Dickinson KC, Lasarev MR, Lee ES. Associations between race and ethnicity and receipt of advice about alcohol use in the Department of Veterans Affairs. Psychiatr Serv. 2009;60(5):663-70. doi:10.1176/appi.ps.60.5.663.

41. Ilgen MA, Price AM, Burnett-Zeigler I, et al. Longitudinal predictors of addictions treatment utilization in treatment-naïve adults with alcohol use disorders. Drug Alcohol Depend. 2011;113(2-3):215-21. doi:10.1016/j. drugalcdep.2010.08.006.
42. Wooten NR, Mohr BA, Lundgren LM, et al. Gender differences in substance use treatment utilization in the year prior to deployment in Army service members. J Subst Abuse Treat. 2013;45(3):257-65. doi:10. 1016/j.jsat.2013.04.001.

43. Glass JE, Kristjansson SD, Bucholz KK. Perceived alcohol stigma: factor structure and construct validation. Alcohol Clin Exp Res. 2013;37(Suppl 1):E237-46. doi:10.1111/j.1530-0277.2012.01887.x.

44. Fortney J, Mukherjee S, Curran G, Fortney S, Han X, Booth BM Factors associated with perceived stigma for alcohol use and treatment among at-risk drinkers. J Behav Health Serv Res. 2004;31(4):418-29. doi:10.1097/00075484-200410000-00006.

45. Glass JE, Mowbray OP, Link BG, Kristjansson SD, Bucholz KK. Alcohol stigma and persistence of alcohol and other psychiatric disorders: A modified labeling theory approach. Drug Alcohol Depend. 2013;133(2):685-92. doi:10.1016/j.drugalcdep.2013.08.016.

46. Wirth JH, Bodenhausen GV. The role of gender in mental-illness stigma: a national experiment. Psychol Sci. 2009;20(2):169-73. doi:10.1111/j.14679280.2009.02282.x.

47. Vinson DC, Turner BJ. Msed, Manning BK, Galliher JM. Clinician Suspicion of an Alcohol Problem: An Observational Study From the AAFP National Research Network. Ann Fam Med. 2013;11(1):53-9. doi:10.1370/ afm. 1464.

48. Glass JE, Bucholz KK. Concordance between self-reports and archival records of physician visits: a case-control study comparing individuals with and without alcohol use disorders in the community. Drug Alcohol Depend. 2011;116(1-3):57-63. doi:10.1016/j.drugalcdep.2010.11.021.

49. Killeen TK, Brady KT, Gold PB, Tyson C, Simpson KN. Comparison of self-report versus agency records of service utilization in a community sample of individuals with alcohol use disorders. Drug Alcohol Depend. 2004;73(2):141-7.

50. National Institute on Alcohol Abuse and Alcoholism. A Pocket Guide for Alcohol Screening and Brief Intervention. Bethesda, MD; 2005.

51. Brown RL, Smith MA. Population-Level Quality Measures for Behavioral Screening and Intervention. Am J Med Qual. 2015. doi:10.1177/ 1062860615577131. 